\section{La modalización discursiva en textos de José Martí para la sección Correo de los teatros, de la Revista Universal (México, 1875- $1876)^{1}$}

Yamilé Pérez GARCÍA (UCLV) yamilep@uclv.edu.cu
GARCÍA, Yamilé Pérez. La modalización discursiva en textos de José Martí para la sección Correo de los teatros, de la Revista Universal (México, 1875-1876). Entrepalavras, Fortaleza, v. 6, n. 2, p. 182-198, jul./ dez. 2016.

Resumen: Este es un estudio que trabaja con textos escritos por José Martí entre 1875 y 1876 para la Revista Universal de México, desde un enfoque analítico discursivo. Se propone describir el uso de los modalizadores del enunciado y la enunciación como indicadores de la subjetividad del emisor, identificando la perspectiva individual y la plural, en tanto representante de la publicación. Luego de una breve explicación teórica acerca de los modalizadores del discurso, construida a partir de los criterios de Bosh (1999), Figueras (2001), Grau Tarruell (2003) y Losada García (2011), entre otros, se arriba a conclusiones acerca de los modalizadores más comunes en los textos revisados y su implicación semántico-pragmática.

Palabras clave: Modalización. Discurso. Elementos modalizadores. Enunciado. Enunciación.

1 Este artículo es resultado del proyecto institucional de investigación de la Universidad Central «Marta Abreu» de Las Villas: Análisis del discurso en obras literarias, académicas y lexicográficas de la variante cubana del español, dirigido por la Dra. Mercedes Garcés Pérez. 
Abstract: This is a study based on the texts written by Jose Marti between 18751876 for the mexican Revista Universal, from a discursive-analytical approach. The purpose is to describe the statements modalizers and the statement as indicator of the transmitter's subjectivity, identifying the individual perspective as well as the plural, as long as it represents the publication. After a brief theoretical explanation of discourse modalizers, built upon the criteria expressed by Bosh (1999), Figueras (2001), Grau Tarruell (2003) and Losada García (2011), among others, conclusions are reached around the most common modalizers in revised texts along with its semantic-pragmatic implications.

Keywords: Modalization. Discourse. Modalizing elements. Statement.

\section{Introdução}

La subjetividad del hablante, voluntaria o involuntariamente, aparece expresada explícitamente no solo en la lengua oral sino en el texto escrito. Claro que la expresión de la subjetividad no es siempre similar en los diferentes tipos de texto, pues si bien este fenómeno se trata de evitar en el texto científico en pos de la objetividad en un entorno en el que cualquier grado de expresión individual constituye un pecado - y los textos resultantes son, por ende, muestra y expresión de la impersonalidad-, en otros textos se exacerba la presencia del emisor en función de la expresividad o de alcanzar determinada reacción en el receptor.

En el caso del texto periodístico, el profesional especializado en cualquiera de sus géneros debe seguir y respetar, ciertamente, los intereses y principios del medio para el que escribe, hablar por él o en su nombre. Sin embargo, es común que emita juicios personales y manifieste su parecer sobre cualquier asunto en sus textos, voluntaria o involuntariamente. De esta forma, la subjetividad, la opinión personal, los juicios de valor de los periodistas se manifiestan en sus comunicaciones. Al respecto, Teramo y Vernino (2003) consideran que «cada diario [o cualquier publicación periódica] sigue una línea editorial que está estrechamente ligada a la ideología que sustenta. Esta se manifiesta, fundamentalmente, en el lenguaje utilizado en los editoriales del diario. Sin embargo, observamos marcas valorativas de los hechos en las informaciones noticiosas ».

La expresión de la valoración personal explícita o implícita es un tema atendido por la Lingüística y la Pragmática, área donde el fenómeno se ha denominado modalización del discurso. Con el objetivo de comprobar cuáles son, entre los modalizadores generales descritos por la teoría, los recursos de la lengua responsables de la expresión de 
v. 6 (2)

$182-198$

$\mathrm{jul} / \mathrm{dez}$

2016

la subjetividad de José Martí en su labor periodística, y de determinar aquellos que podrían caracterizar estilísticamente estos trabajos, el presente artículo utiliza un corpus textual, conformado por trabajos escritos para la sección Correo de los Teatros, de la Revista Universal de México.

\section{La expresión textual de la subjetividad: modalización del discurso}

En la tesis doctoral La modalització: manifestacions de la subjectivitat lingüística en els discursos acadèmics orals i escrits (2003), Maria Grau Tarruell se ha referido a este fenómeno en tanto el sujeto hablante es la pieza clave de la comunicación y cuando habla interpreta el mundo a través de su propio psiquismo, quiere dar cuenta de los distintos recursos de que dispone para manifestar abiertamente sus actitudes (y construir así un texto de los llamados subjetivos) o para disimularlas (y producir un texto aparentemente objetivo). Efectivamente, aunque la autora trabaja con textos académicos, que deben ser por fuerza objetivos, los juicios individuales sobre lo dicho y sobre las formas en que se dice afloran en la producción lingüística, aun disimuladamente. En otros tipos de texto no es interés el soslayo o la expresión oblicua de la subjetividad, sino que puede constituir un objetivo claro, como el caso que ocupa aquí, en tanto se persiga convencer, formar opinión o al menos promover la reflexión sobre algún asunto bajo principios comunes.

Más adelante, esta autora define la modalización como «un concepto pragmático que se refiere a las actuaciones concretas de los hablantes que producen enunciados en los que dejan trazas de su manera de pensar y de sentir, de sus actitudes » . (Ídem) De ahí que Marcia Losada (2011) lo defina como uno de los componentes que permite relacionar el nivel semio-enunciativo (discurso) con el nivel semio-cognitivo (sistema subyacente).

Según Carolina Figueras, hablar de modalización del discurso comprende dos dimensiones: la modalización de la enunciación y la modalización del enunciado. En primer lugar, la modalización de la enunciación es aquella que se refiere a la actitud del emisor ante el receptor - responsable de la distinción de los actos de habla (AH) en declarativos, interrogativos e imperativos - ; y en segundo lugar, se trata de la modalización del enunciado, mediante la cual se consideran los hechos expresados o la información como verdaderos, necesarios 
o posibles, o se expresan juicios apreciativos o valorativos sobre el mensaje (2001, p. 128).

Por su parte, para definir la modalidad discursiva Elena Bosh apunta: «constituye el soporte de la verdadera comunicación emotiva que supone la existencia de formas explícitas, de expresiones lingüísticas, que transmiten significados implícitos y en las que las formas explícitas, a través de recursos lingüísticos, apelan a la emotividad y apuntan hacia posibles interpretaciones implícitas. Esta es sin duda, la explicación que hace Bally sobre la oración, compuesta por modus (modalidad) y dictum (contenido de la proposición)» (1999, p. 142). Según esta idea, no sería posible evitar que salga a la luz la subjetividad en la producción lingüística, ya sea más o menos explícita. De esta forma, la modalización está siempre presente en la actividad discursiva. La participación del emisor o la implicación de este en el discurso y con otros actantes se conforman de forma opuesta al distanciamiento o la impersonalidad.

Esta autora destaca la diversidad de enfoques que, en lingüística, se han utilizado para referirse al término modalidad. Así, sintetiza que se ha entendido «(i) como un estado mental interior del hablante; (ii) como identificación emotiva del hablante con sus actos de habla; (iii) como una manera de establecer relaciones; (iv) como recurso retórico (estrategias retóricas y estilísticas); (v) como implicación del hablante en sus discursos; (vi) como meta-mensaje para establecer relaciones». (Ídem)

Otros $^{1}$ han considerado que para entender el fenómeno, resulta más provechoso la distinción de la modalización en valorativa, epistémica y deóntica.

La modalización valorativa se manifiesta al hallar en el mensaje expresiones o juicios de valor sobre lo expuesto. Los recursos mediante los cuales se identifica esta forma de modalización son: vocablos apreciativos o despreciativos, la cuantificación de lo dicho mediante adverbios y otras expresiones de cantidad, figuras literarias de ponderación, etc.

La modalización epistémica, por su parte, se manifiesta cuando el hablante declara el grado de certeza de su mensaje. Son comunes expresiones mediante las cuales el emisor presenta sus enunciados como incuestionables - está claro que, es evidente, indudablemente o como posibles - en este caso, a través de expresiones del tipo de quizás, es posible, imagino que.

1 Al respecto pueden revisarse los trabajos de María Teresa Teramón y Teresita María Vernino (2003), «Medición de la subjetividad en la prensa escrita»; «Oración, modalidad deóntica y valoración», de María Eugenia Vázquez; o «Subjetividad y modalidad lingüística», de María Encarnación Pérez Sedeño, entre otros. 
v. 6 (2)

$182-198$

$\mathrm{jul} / \mathrm{dez}$

2016

Por último, la modalización deóntica del texto se expresa cuando el emisor se dirige al receptor para expresarle la necesidad o conveniencia de actuar por motivos éticos o morales. Se logra esta modalización mediante el uso del imperativo, perífrasis con verbos modales, verbos de obligación, etc.

Una clasificación modificada a partir de la modalización de esta tríada defiende Grau Tarruell (2003) cuando añade a esta lista la modalización díctica y la reflexiva:

- Modalización apreciativa - o valorativa-: conectada con la expresión de juicios de valor.

- Modalización epistémica: conectada con el grado de certeza.

- Modalización deóntica: conectada con la expresión de la obligación.

- Modalización díctica: conectada con la inscripción en el texto de los interlocutores y con las relaciones que se establecen entre ellos.

- Modalización reflexiva: comentarios que el enunciador hace de sus palabras.

Los elementos responsables de la modalización del discurso pueden estar implícitos - como la ironía - o explícitos. En la revisión realizada para este estudio resulta coincidente la idea de que no hay un nivel de la lengua donde se inscriban los recursos que intervienen en la modalización discursiva, sino que en todos ellos pueden hallarse elementos que tributen a la expresión de la modalidad. De ahí que Marcia Losada haya considerado como constituyente ilocutivo-modalreferencial a la «expresión lingüística de cualquier longitud y rango que evidencia y realiza en el enunciado el producto de la intención y actitud en el discurso del locutor. (2011)

Ciertamente, lo que permite comprender la subjetividad del hablante es la relación de estas estructuras con el contexto discursivo. Al respecto, en el Centro Virtual Cervantes se recoge:

- pueden ser mecanismos prosódicos (como la entonación o las pausas);

- morfológicos (como el modo subjuntivo, indicativo, etc.);

- sintácticos (formas de focalización, impersonalización, etc.); 
- léxicos (adjetivos como deseable, cierto, etc.);

- textuales (marcadores como francamente);

- metaenunciativos, es decir, muestran la actitud con la que el hablante se presenta a sí mismo en el texto (si puedo decir, de algún modo);

- tipográficos (como las comillas)²

Entre los modalizadores por excelencia la teoría revisada para este artículo ha considerado elementos lingüísticos de naturaleza diversa, donde se comprenden determinadas clases de palabras, funciones sintácticas, cuestiones ortográficas y tipográficas, clases de expresiones... A saber, se habla de la modalización a través de la presencia de:

1. Adverbios modalizadores. En este caso, se trata de adverbios que modifican al enunciado completo y no a uno de sus componentes. Con ellos el emisor expresa su juicio sobre la información del enunciado y refiere su actitud ante lo dicho. Entre los más comunes figuran afortunadamente, indudablemente, felizmente...

2. Los deícticos. Elementos del lenguaje que intervienen en la deixis personal, espacial, temporal, situacional y social ${ }^{3}$, pues enmarcan las personas que intervienen en el acto comunicativo y la naturaleza de las relaciones entre ellas, apuntan hacia características espacio-temporales de la situación, etc.

3. Expresiones de valoración. Aquí pueden aparecer tanto verbos que expresan valoración como sustantivos o adjetivos valorativos del tipo de creer, alegrarse, acongojarse, acierto, éxito, logro, disgusto, estupidez, error, lamentable, grave, inconcebible, excesivo, acierto..., respectivamente.

4. Cuantificadores. Mediante la expresión de la cantidad también se valora el discurso, tanto la información

2 Para más información al respecto, puede consultarse el sitio http://cvc.cervantes.es/ ensenanza/biblioteca_ele/diccio_ele/diccionario/modalizacion.htm

3 Para profundizar en el tema de la deixis, su implicación semántico-pragmática y como elemento de modalización, pueden consultarse: Lengua y espacio. Introducción al problema de la deíxis en español, de José Cifuentes Honrubia, La deixis: egocentrismo y subjetividad en el lenguaje, de Juan Antonio Vicente Mateu, o «La deixis social como concepto pragmático en la interpretación sociolingüística», de Encarnación Pérez García. 
v. 6 (2)

$182-198$

$\mathrm{jul} / \mathrm{dez}$

2016

expresada como el propio enunciado. Puede realizarse con adverbios de cantidad, sufijos y prefijos diminutivos, aumentativos o de intensificación, sustantivos con claros rasgos semánticos de cantidad o volumen como enormidad, montón, pizca...

5. Modalidad oracional. La actitud de hablante en las oraciones enunciativas, exhortativas, desiderativas, interrogativas, dubitativas e imperativas expresan también modalidad discursiva. En particular, en ellas se destaca el grado de certeza que posee el emisor ante lo dicho.

6. Figuras retóricas valorativas. A través de ellas el hablante expresa una opinión sobre los hechos y emite juicios de valor acerca de la información.

7. Recursos tipográficos y signos de puntuación. La cursiva, la negrita, la mayúscula, el subrayado, los paréntesis y guiones largos en los incisos, revelan la subjetividad del emisor ante los hechos y ante el mensaje.

Como se ha visto, la expresión de la subjetividad abarca tanto recursos lingüísticos, como aspectos de entonación y hasta cinéticos. Estos recursos no son privativos de la modalización valorativa, epistémica o deóntica, o de la modalización del enunciado o de la enunciación, sino que pueden incidir en cualquiera de estas dimensiones de la modalización del discurso, debido a su carácter no excluyente.

\section{Los trabajos de José Martí para el Correo de los teatros}

Entre los textos donde el cubano universal José Martí hizo gala de sus dotes de periodista y crítico de arte se encuentran sus trabajos para la sección Correo de los Teatros, de la Revista Universal de México. Publicados en el lapso comprendido entre 1875 y 1876, de extensión variable y con el objetivo de promover el arte dramático, aparecen recogidos ahora en un número de treinta y cinco en el cuarto tomo de la edición crítica de las Obras completas. ${ }^{4}$ Los textos de esta serie obedecen a variados temas relacionados con el mundo dramático: unos anuncian obras teatrales que serán representadas en los teatros mexicanos;

4 Los textos martianos citados en el presente artículo se localizan de las páginas 15 a la 90 de esta fuente. Para evitar reiteraciones innecesarias, en la referencia de los ejemplos se prefirió señalar la fecha de publicación de los textos en la Revista Universal. 
otros constituyen verdaderos estudios acerca de la trayectoria de personalidades de de las tablas (autores o actores); en no pocos se hace crónica de las funciones al comentar sobre la concurrencia, la calidad y pertinencia de los programas teatrales, la acogida de la obra por el público, los sucesos de loa a músicos, directores, autores y actores; y algunos constituyen verdaderos ejercicios de crítica a las puestas en escena, por referirse a la calidad de las actuaciones, al desempeño y trayectoria de artistas o al impacto de la obra en el público y en la historia cultural mexicanos.

A pesar de que Martí consideró en algún momento que sus trabajos para esta serie no eran menos que frívolos, ${ }^{5}$ estos textos exceden lo meramente informativo para expresar valoraciones y hasta tomar tintes moralizantes o aleccionadores. Lejos de concordar con su menosprecio, hay que considerar que en sus correos de teatros se demuestran sus principios de humanista, sus capacidades de intelectual y su sensibilidad para esta manifestación artística, tanto para apreciar las puestas en escena como para realizarles rotundas y acertadas críticas, sin perder la oportunidad de reflexionar a partir de comportamientos humanos y de expresar claramente su criterio.

La opinión personal, sus profundos y más sinceros criterios sobre el mundo teatral mexicano, en fin, su subjetividad salgan a flote en sus trabajos para la Revista a través de diversos recursos. Con las armas de la lengua, Martí se refleja en su accionar discursivo. Este elemento, de intención pragmática en tanto busca acercar al receptor a su parecer y formar así su opinión al tiempo que le instruye en los componentes del mundo dramático, es relevante para la descripción del estilo martiano.

Ahora bien, la subjetividad en un mensaje lingüístico se puede manifestar a nivel locutivo, ilocutivo y perlocutivo, mediante la inserción de indicaciones que aportan modalidad. Esta es, por tanto, uno de los componentes que señala la posición subjetiva o la actitud del locutor del discurso ante los referentes, el contexto y la situación comunicativa. Las posturas ilocutivo-modales se expresan emitiendo lingüísticamente un enunciado con expresiones de modalidad, o simplemente conformándolo con una estructura equis. Esto último, como considera Marcia Losada (2011), presupone una toma posición subjetiva previa ante lo focalizado. Hasta donde se ha revisado, las formas de expresión de la

5 En su trabajo publicado el 28 de diciembre de 1875 en la Revista Universal dice: «ya van escritas más cuartillas de las que para este frívolo correo de teatros, fuera menester». 
v. 6 (2)

182-198

$\mathrm{jul} / \mathrm{dez}$

2016

subjetividad martiana en sus trabajos periodísticos no han sido suficientemente estudiadas, a diferencia de otros aspectos compositivos de su estilo. A partir de esta motivación inicial, en este artículo se describen las formas de expresión de la subjetividad martiana mediante la modalización discursiva de sus juicios, lo cual constituye una de las aristas de la manifestación textual de los pareceres individuales.

\section{La modalización del discurso en Correo de los Teatros}

Al tratarse de trabajos escritos para una publicación periódica, la Revista Universal, hay que considerar que los elementos modalizadores matizarán un discurso plural, en tanto el Martí crítico de la escena se ubica en un emisor en primera persona del plural, en detrimento de la impersonalidad. De esta forma expresa la concordancia entre sus opiniones y la de la dirección de la revista.

Así se observa, por ejemplo, el uso común de formas verbales en esta persona gramatical en casos como los que siguen.

Espacio más digno de ella y concurrencia más numerosa deseamos para la vez próxima en que la excelente actriz cubana vuelva a presentarse a nuestro público. (Revista Universal, 9 de junio de 1875)

Antes nos incomodan que nos placen esas notas altas que ningún arte prueban y que revelan solo una poderosa fuerza de voz. (Revista Universal, 26 de junio de 1875)

Esta simple manifestación de la presencia del sujeto hablante mediante la forma verbal puede aparecer modalizada por añadidura a través de vocablos o frases que enfaticen la individualidad - como con la frase con nuestro propio juicio en el primer ejemplo aquí debajo - o donde se exprese la modalidad de la acción verbal - como sucede con el segmento con regocijo, en el segundo caso.

En las columnas de la Revista se publicaron algunas líneas biográficas de la que hoy podemos llamar con nuestro propio juicio excelente actriz (Revista Universal, 9 de junio de 1875) Nosotros vemos siempre con regocijo trabajar a la señorita Padilla. (Revista Universal, 28 de diciembre de 1875) 
Para describir cómo se manifiesta la modalización discursiva en los correos martianos, se consideró pertinente readecuar las distinciones de la modalización defendidas anteriormente, de tal forma que se considera la modalización de tipo valorativa y la epistémica como dimensiones de la expresión modal del enunciado y la modalización deóntica como expresión modal de la enunciación.

Modalización del enunciado

La modalización del enunciado comprende la expresión de la subjetividad del hablante hacia los hechos de la realidad, los referentes o la información. En los casos que siguen, los vocablos y frases subrayadas expresan la valoración martiana sobre tales.

Ante concurrencia tristemente escasa tuvo lugar antenoche en el Gran Teatro Nacional, la función dramática anunciada a beneficio de los sombrereros en huelga. (Revista Universal, 9 junio de 1875)

tal es la nueva actriz que se presenta a nuestro público y tales condiciones se han revelado en ella, a pesar de la triste impresión que debió hacer en su ánimo, presentarse ante un teatro vacío, en el que por fortuna hubo algunas personas capaces de estimar su indudable valer. (Revista Universal, 9 junio de 1875)

Estos dos primeros ejemplos constituyen una muestra de la valoración de José Martí sobre hechos o acontecimientos, mientras que los casos que siguen manifiestan a través del modalizador, su opinión acerca de objetos y actitudes

Aquellas vigas informes de los palcos, son ahora columnas bien pintadas de blanco y de oro (Revista Universal, 8 agosto de 1875) Indudablemente, la actriz padecía alguna enfermedad, y se la obligó tiránicamente a trabajar enferma. (Revista Universal, 14 de marzo de 1876)

Herrera, el pintor de La paloma azul, hace para el remozado coliseo, sorprendentes decoraciones fantásticas: y a fe que lo hace bien el recién laureado pintor. (Revista Universal, 8 agosto de 1875) 
v. 6 (2)

$182-198$

$\mathrm{jul} / \mathrm{dez}$

2016
El Sr. Freyre, que ha adelantado visiblemente, no debe volver a morir como murió antenoche. (Revista Universal, 15 de junio de 1876)

En este último caso, el modalizador expresa una valoración de la calidad del artista, mientras que a continuación aparece un caso donde la opinión que se vierte se refiere a la pertinencia en la planificación y organización del programa de función.

Algo menor fue, sin embargo, el entusiasmo del público, cosa explicable quizás por la composición un tanto extensa y larga del programa. (Revista Universal, 26 de junio de 1875)

Obsérvese cómo en los casos anteriores los moralizadores del discurso expresan la valoración del emisor individual, responden a un criterio propio que no necesariamente tiene que coincidir con la opinión del medio, en tanto refieren sentencias más personales. Como se ve, resaltan aquí los modalizadores por excelencia, los adverbios de modo y frases con sentido de cuantificación de las cualidades expresadas por adjetivos, como el caso de un tanto.

Otra forma común en que se modalizan los enunciados martianos es a través de la confirmación de la veracidad de lo dicho. De tal forma resulta la modalización epistémica, que los hechos o la información se expresan en términos de verdad, tanto cuando se trata de valoraciones sobre sucesos, como cuando Martí presenta sus reflexiones aforísticas, como en el último caso de los que siguen.

Tenían los actores del Principal toda su esperanza en La fille Angot, sin razón indudablemente para tenerla, y no podían ver tranquilos la ruidosa y triste manera con que venían a tierra sus esfuerzos. (Revista Universal, 4 septiembre de 1875) Si Dios es todo lo bueno, aunque en filosofía va siendo muy abstracta esta imagen de Dios, indudablemente esa santa madre es su imagen. (Revista Universal, 28 diciembre de 1875) Freyre merece especial mención, porque realmente hizo algo bueno en su papel. (Revista Universal, 13 enero de 1876)

Indudablemente, la actriz padecía alguna enfermedad, y se la obligó tiránicamente a trabajar enferma. (Revista Universal, 14 de marzo de 1876) 
En cuanto a los artistas, Villalonga procuró cantar su papel; Arcaraz lo cantó realmente con pasión y sentimiento; la Montañez fue aplaudida en el suyo con justicia; Iglesias no hizo sensible la falta del cómico Darcy, y Castro aventajó sin duda alguna al mofletudo Castel en su risible Bonneteau. (Revista Universal, 6 de junio de 1876)

Indudablemente, el papel de Gil González está hecho para levantar a muy buena altura el drama. (Revista Universal, 4 marzo de 1876)

No fue así en vida, aunque lo más cierto es que nadie sabe cómo fue; pero no cumplía a la actriz crear un personaje oscuro, sino interpretar fielmente el de la obra. (Revista Universal, 1ero de agosto de 1876)

la comedia de Peón ha merecido sin duda el entusiasmo unánime con que por hombres y mujeres fue tan cariñosamente recibida. Y son buenas indudablemente las comedias que gustan a las mujeres. (Revista Universal, 8 de julio de 1876)

En estos fragmentos se destacan como recursos más reiterados los adverbios cuyo significado léxico incluye rasgos semánticos asociados a la certeza, la veracidad.

Obsérvese cómo en el caso siguiente, sin dejar de tratarse de modalización epistémica, la presencia de tal vez modaliza el enunciado en términos de posibilidad, no exactamente de veracidad o certeza.

El El Hereu hay un hombre malo; no gustamos de ver malvados en escena. Ello es verdad que sin él no habría drama; pero tal vez preferiríamos un drama pálido a un drama con traidor. (Revista Universal, 11 diciembre de 1875)

Cuando aparece un modalizador del tipo verdad, verdaderamente, indudablemente, calificando un adjetivo - como en los ejemplos que siguen-, se produce una modalización discursiva que linda entre lo valorativo y lo epistémico. A la vez que cuantifica o amplifica el calificativo, no pierde el modalizador su significado léxico directamente vinculado a la expresión de la certeza, la veracidad. Obsérvese, al respecto, los ejemplos que siguen. 
v. 6 (2)

$182-198$

$\mathrm{jul} / \mathrm{dez}$

2016

Leyeron al mismo tiempo composiciones encomiásticas al talento de la artista, los Sres. Estrada, Alonso y Rodríguez, entre ellas una verdaderamente bella del joven poeta Francisco Ortiz. (Revista Universal, 9 de junio de 1875)

Representaron el domingo una pieza nueva, original del joven Velázquez, desconocido absolutamente hasta ayer, pobre humilde y en verdad inteligente. (Revista Universal, 20 julio de 1875)

¿Es buena? Indudablemente. (Revista Universal, 11 diciembre de 1875)

Su tercer acto es verdaderamente admirable: magistral es la terminación del acto segundo. (Revista Universal, 15 de febrero de 1876)

Al tratarse de los moralizadores del enunciado, son comunes los adverbios amplificadores o reductores de las cualidades expresadas por adjetivos. Así, a través de estos recursos se cuantifica la valoración martiana sobre hechos, objetos, actitudes y aptitudes de artistas, instituciones y puestas en escena del ámbito teatral mexicano de la época.

Modalización de la enunciación

Cuando se trata de modalización de la enunciación, debe considerarse como tal la de naturaleza deóntica, en tanto constituye la calificación modal de los actos de habla. Esa forma de modalización apunta hacia los actos locutivos, ilocutivos y perlocutivos.

En los locutivos, como cuando se trata de declarar o informar sobre algo, la valoración martiana sobre sus propios actos de habla puede aparecer expresada a partir de moralizadores de las formas verbales, como los subrayados en los casos que siguen.

Con placer consignamos que antenoche huno en el Nacional un lleno caso completo: bien lo merecía la Sra. Visconti. (Revista Universal, 29 junio de 1875)

Digamos, y con especial encomio, que la Srta, Servín removió todas sus notables fuerzas artísticas, y creó con ellas un papel que Teodora Lamadrid, con valer tanto, no supo hacer tan altivo, tan vivo, tan enérgico. (Revista Universal, 28 enero de 1876) 
Recordamos con placer la manera con que en las representaciones últimas le oímos el famoso Miserere. (Revista Universal, 26 junio de 1875)

En los perlocutivos, como los que van desde la sugerencia solapada hasta la orden o mandato, se hallan también modalizadores de las acciones expresadas por las formas verbales, como se observa a continuación.

Es seguro que Guasp pondrá en escena ambas obras, tan pronto como las reciba. (Revista Universal, 4 febrero de 1876)

Obsérvese cómo ahora la sugerencia se esconde tras la afirmación de la veracidad mediante el modalizador es seguro / de seguro y se reafirma con la presentación de un argumento tras los dos puntos.

De seguro que será tan abundante como distinguida la concurrencia que asista a la función de la Sra. Visconti: no olvide el público que con ella va a prestar a la estimable cantactriz un verdadero servicio. (Revista Universal, 26 de junio de 1875)

El adverbio afectuosamente, utilizado en el fragmento aquí debajo, suaviza la orden ya atenuada con el verbo indicar, a diferencia del ejemplo siguiente, en el cual se manifiesta la sugerencia o la orden tras la expresión de deseo y el modalizador prontamente.

Guerra es tan complaciente como buen actor; él hará de seguro lo que le indicamos afectuosamente aquí. (Revista Universal, 8 agosto de 1875)

El acontencimiento de la noche, que deseamos ver prontamente repetido de un modo más solemne y digno de ella, fue la presentación al público mexicano de la joven actriz Sra. Eloísa Agüero de Osorio. (Revista Universal, 9 de junio de 1875)

En el ejemplo que se transcribe a continuación, el adverbio modalizador se refiere la acción prometida. 
v. 6 (2)

$182-198$

jul/dez

2016

Para el domingo próximo reservamos completar concienzudamente nuestro juicio. (Revista Universal, 15 de junio de 1876)

En los casos siguientes, los modalizadores calurosamente y cariñosamente referidos a la felicitación, manifiestan el sentir de la Revista y el propiamente martiano. Lo mismo sucede con la expresión con el alma, del último ejemplo.

La redacción de la Revista felicita calurosamente al poeta y a los actores, y envía su última palabra, no a Peón a quien no hace falta este humilde óbolo nuestro, sino a México, que posee un hijo que lo honra y lo enaltece. (Revista Universal, 30 de abril de 1876)

Cariñosamente felicitamos por su éxito al poeta, que recibía conmovido las felicitaciones de sus amigos numerosos. (Revista Universal, 29 de agosto de 1876)

Le deseamos con el alma un éxito completo, y con cariño nos preparamos a tomar parte en él. (Revista Universal, 29 de agosto de 1876)

Finalmente, se halla también un caso donde el modalizador resulta índice claro del reproche a los lectores - reproche sugerido, no directo-mediante el conector sin embargo, ubicado tras la forma verbal y aislado sintácticamente en el enunciado mediante las comas.

Y aún pareció menor la concurrencia porque se perdía en el ancho espacio del teatro Nacional: motivo había, sin embargo, para que un público numeroso hubiese presenciado la función. (Revista Universal, 9 de junio de 1875)

\section{Conclusiones}

Como se ha visto, a través del estudio de la modalización discursiva en los textos martianos, lejos de tratarse de frívolos mensajes sobre la cultura escénica mexicana, los trabajos escritos para el Correo de los Teatros expresan la valiosa opinión de su autor en tanto crítico de arte y observador ferviente de los tipos humanos.

Se ha comprobado la eficiencia de los recursos advertidos por los 
estudios teóricos sobre el tema en la prosa martiana. Se ha determinado que, además del uso de la primera persona del plural y la presencia de pronombres en asociados a esta persona gramatical, que incluyen explícitamente la voz autoral en la opinión expresada, se destaca el empleo de los adverbios terminados en -mente tanto en la modalización del enunciado como de la enunciación.

El empleo de frases preposicionales del tipo por fortuna, con placer, con el alma, para indicar modalidad de las formas verbales; la ponderación de adjetivos a través de adverbios y frases que indican cuantificación (del tipo de bien y un tanto); y de estructuras diversas (adverbios y locuciones adverbiales: realmente, sin duda, de seguro; o estructuras oraciones fijas como lo más cierto es, es seguro) que reafirman la veracidad de las opiniones explicitadas, resultan las formas más recurrentes de expresión de la modalidad en estos trabajos martianos.

Ya sea desde una voz plural que expresara la opinión del medio para el que escribió o a través de determinados recursos modalizadores - adverbios, frases preposicionales y otras expresiones - se evidencia la valoración del enunciado - entendida como la dimensión referencial de los mensajes - . De igual forma, los modalizadores utilizados su discurso expresan valoración de la enunciación, en tanto Martí se ubica desde una posición externa al modalizar sus propios actos de habla.

Mediante la inserción de tales indicaciones modalizadoras el lector experimenta un acercamiento a la individualidad del sujeto hablante que no deja de sorprender aún por aquellas «ligeras » opiniones suyas acerca del mundo dramático.

\section{Referências}

BOSH, E. La modalización. Ejemplo del discurso subjetivo en un texto persuasivo. ASELE Actas X, 1999. en http://cvc.cervantes.es/ensenanza/ biblioteca_ele/asele/pdf/10/10_0139.pdf.

FIGUERAS, C. Pragmática de la Puntuación, 180 pp., UEB-Octaedro, Barcelona, 2001. (ISBN 84-8063-468-5)

GRAU TARRUELL, M. La modalització: manifestacions de la subjectivitat lingüística en els discursos acadèmics orals i escrits, tesis doctoral, (reseña), Departamento de Filología Catalana, Universitat Autònoma de Barcelona, 2003. En http://www.uab.cat/uabdivulga/cast/tesis/2003/discurs1203.htm

LOSADA GARCÍA, M. La máscara del lenguaje. Intencionalidad y sentido, 167 pp., Editorial Ciencias Sociales, La Habana, 2011. (ISBN 978-959-06-1326-5)

MARTÍ, J. Obras completas. Edición crítica, tomo 4, pp. 15-90, Centro de 
v. 6 (2) 182-198 $\mathrm{jul} / \mathrm{dez}$ 2016
Estudios Martianos, La Habana, 2001. (ISBN 959-7006-36-7)

PÉREZ SEDEÑO, M. E. Subjetividad y modalidad lingüística, EPOS, Revista de filología, no.17, pp.57-70, 2001. (ISSN 0213-201X) En http://revistas.uned.es/ index.php/EPOS/article/viewFile/10179/9718

TERAMÓN, M. T. ; VERNINO T. M. Medición de la subjetividad en la prensa escrita, Comunicación y sociedad. 2003, vol. XVI, núm.1, p. 139-155. En http:// dadun.unav.edu/bitstream/10171/8044/1/20091007103431.pdf।

(s.d.e) La modalización como forma de adecuación textual, en https:// fermoni.files.wordpress.com/2012/12/la-modalizacic3b3n-como-forma-deadecuacic3b3n-textual.pdf

Recebido em: 15 de fev. de 2016. Aceito em: 18 de jul. de 2016. 